Nota / Note

\title{
QUALIDADE FISIOLÓGICA E TAMANHO DE SEMENTES DE CENOURA
}

\author{
Angelica Brod Rodo ${ }^{1 *}$; Cleiton Stigger Perleberg${ }^{1}$; Salvador Barros Torres ${ }^{1}$; Daniel Felipe de \\ Oliveira Gentil1'; João Tessarioli Neto² \\ ${ }^{1}$ Pós-Graduandos do Depto. de Produção Vegetal - USP/ESALQ. \\ ${ }^{2}$ Depto. de Produção Vegetal - USP/ESALQ, C.P. 9 - CEP: 13418-900 - Piracicaba, SP. \\ *Autor correspondente <abrodo@carpa.ciagri.usp.br>
}

\begin{abstract}
RESUMO: A maturação de sementes de cenoura ocorre escalonadamente nas umbelas de diferentes ordens e, sendo a colheita realizada em uma única etapa, pode ocorrer desuniformidade de tamanho, dentro de um mesmo lote de sementes. Desta forma, este trabalho foi realizado visando determinar o efeito do tamanho da semente na sua qualidade fisiológica. Quatro lotes de sementes comerciais de cenoura cv. Brasília, provenientes da região de Bagé-RS, foram separados em três frações: grande (retenção em peneira de perfuração redonda $2 \mathrm{~mm}$ ); média (retenção em peneira de perfuração redonda $1,5 \mathrm{~mm}$ ) e a mistura entre grande e média (em porções iguais). Foram conduzidos os seguintes testes: germinação, tetrazólio, condutividade elétrica, envelhecimento acelerado e emergência de plântulas em casa de vegetação. Não houve diferenças significativas quanto aos diferentes tamanhos de sementes em todos os testes realizados, com exceção do teste de emergência de plântulas em casa de vegetação com avaliação aos 14 dias após a semeadura. Porém, este teste não mostrou consistência na separação das frações em diferentes níveis de qualidade, para os diferentes lotes.
\end{abstract}

Palavras-chave: Daucus carota, semente, vigor, germinação

\section{CARROT SEED SIZE AND PHYSIOLOGICAL QUALITY}

\begin{abstract}
Maturation of carrot seeds occurs in a sequence based on the different orders of the umbel. Since harvest is carried out only at one stage, nonuniform seed sizes within the same seed lot may occur. The effect of seed size on physiological quality was determined. Four lots of commercial carrot seeds (cv. Brasília) were separated in three fractions: large (retention at $2 \mathrm{~mm}$ diameter); medium (retention at $1.5 \mathrm{~mm}$ diameter) and a mixture of large and medium seeds (1:1 proportion). These fractions were tested for germination, tetrazolium reduction, electrical conductivity, accelerated aging and seedling emergence. Only seedling emergence, evaluated after 14 days, showed statistical difference. However this test did, not show consistency for the separation of the fractions into different quality levels, for different lots.

Key words: Daucus carota, seed, vigor, germination
\end{abstract}

\section{INTRODUÇÃO}

No florescimento, a cenoura (Daucus carota L.) emite a haste floral principal, contendo no ápice uma inflorescência central, denominada primária ou de primeira ordem, que se ramifica dando origem a umbelas secundárias, terciárias e quaternárias. 0 tamanho da umbela decresce a medida que cresce 0 número de ordem, sendo que as quaternárias, se existentes, normalmente produzem poucas sementes. As umbelas de diferentes ordens têm florescimento, antese e maturação de sementes em épocas cronologicamente diferentes, iniciando pela umbela primária, seguida pelas secundárias e assim sucessivamente (Hawthorn et al., 1962).

Para a produção de sementes, pode-se adotar a prática da colheita por umbelas ou por ordem de maturação, ou ainda, colher a planta toda quando a umbela terciária estiver madura (Reghin et al., 1985), sendo que neste método as perdas são elevadas pelo fato de ocorrer a debulha natural. Segundo Castro (1971), a colheita realizada quando as umbelas de terceira ordem ou de maiores números de ordem estão maduras parece ser prejudicial à qualidade das sementes já maduras, por causa da deterioração fisiológica em consequência de fatores ambientais desfavoráveis, embora, algum aumento em rendimento possa resultar dessa prática.

A qualidade é particularmente importante em sementes de hortaliças, não só pelo alto custo de produção, mas também porque a produção de hortaliças envolve, freqüentemente, vultosos investimentos, cujo retorno depende, em grande parte, da qualidade das sementes utilizadas (Bittencourt, 1991).

O tamanho, viabilidade e germinação das sementes de cenoura variam de acordo com o cultivar, lote e época de produção. Tais diferenças tem sido associadas com densidade de plantas, época de colheita das sementes, ordem da umbela de onde as sementes foram colhidas e condições climáticas durante o desenvolvimento e colheita das sementes (Gray et al., 1988). 
No cultivar Brasília, ainda ocorre grande diversidade genética; desta forma, os padrões de qualidade das sementes parecem não estar ainda muito bem definidos, havendo variação na qualidade das sementes em termos de germinação e vigor (Bittencourt, 1991). Umbelas superiores apresentam sementes de maior tamanho, sendo que a germinação e o vigor das sementes, também podem variar de acordo com a ordem das umbelas. Umbelas superiores geralmente apresentam sementes com maior poder germinativo e, segundo Gray \& Steckel (1983), este fato está intimamente relacionado ao comprimento do embrião das sementes.

Krarup \& Villanueva (1977), estudando a qualidade de sementes provenientes de umbelas de diferentes ordens, observaram que existe uma correlação positiva entre o tamanho do embrião e a percentagem de germinação. Nascimento (1991) também observou que o poder germinativo e o vigor das sementes decresceram à medida que aumentava o número de ordem das umbelas. O tamanho da semente, em muitas espécies, é indicativo de sua qualidade fisiológica (Popinigis, 1985). As sementes maiores, normalmente, possuem embriões bem formados e com maiores quantidades de reservas (Carvalho \& Nakagawa, 1983); logo, num mesmo lote, as sementes maiores, potencialmente, apresentam maior poder germinativo e vigor que as sementes menores, embora existam controvérsias quanto aos benefícios da classificação por tamanho.

A influência do tamanho sobre a qualidade fisiológica de sementes de cenoura foi estudado por Austin \& Longden (1967), Jacobsohn (1978), Jacobsohn \& Globerson (1977) e Usik (1980), os quais observaram que as sementes de menor tamanho apresentaram menor percentagem de germinação, emergência em campo e rendimento que as sementes de maior tamanho. A mesma tendência foi verificada nos estudos de Krarup \& Villanueva (1977) e Gray \& Steckel (1983), em que as sementes maiores apresentaram maior peso, embriões maiores e produziram plântulas mais vigorosas.

Este trabalho teve como objetivo avaliar a influência do tamanho de sementes de cenoura na sua qualidade fisiológica.

\section{MATERIAL E MÉTODOS}

O trabalho foi realizado no Laboratório de Análise de Sementes do Departamento de Produção Vegetal, da Escola Superior de Agricultura "Luiz de Queiroz", Universidade de São Paulo, em Piracicaba/SP, no período de abril a junho de 1998.

Foram utilizados quatro lotes de sementes de cenoura (Daucus carota L.) cv. Brasília, produzidas no município de Bagé/RS, na safra 97, pela Empresa Hortec Sementes Ltda. Esta empresa classifica comercialmente seus lotes em sementes grandes e médias e, no presente trabalho, adotou-se a divisão dos lotes em três frações: sementes grandes (retenção em peneira de perfuração redonda $2 \mathrm{~mm}$ ), sementes médias (retenção em peneira de perfuração redonda $1,5 \mathrm{~mm}$ ) e uma mistura, em porções iguais, de grandes e médias.

Os diferentes lotes analisados apresentavam teores de água entre 9,6 e $10,4 \%$ e o peso de 1000 sementes variando entre 0,13 e $0,20 \mathrm{~g}$ nas sementes grandes; 0,13 e 0,14 g nas sementes médias e 0,13 e 0,17 $\mathrm{g}$ na mistura.

As sementes foram analisadas através dos testes descritos a seguir:

Teste de germinação - realizado com quatro repetições de 50 sementes, em caixas gerbox, sobre papel mata-borrão umedecido com água destilada na proporção de 2,5 vezes o seu peso seco, em germinador regulado a $20^{\circ} \mathrm{C}$ e seguindo as demais recomendações das RAS (Brasil, 1992).

Teste de tetrazólio - realizado com duas repetições de 50 sementes, as quais foram previamente acondicionadas em gerbox com papel mata-borrão, umedecido com água destilada na proporção de 2,5 vezes o seu peso seco, durante 60 minutos a $25^{\circ} \mathrm{C}$. Após este período, as sementes foram seccionadas por um corte longitudinal ao longo do lado do embrião e, imediatamente, embebidas na solução de tetrazólio a $0,1 \%$, durante 60 minutos a $35^{\circ} \mathrm{C}$, após o qual foram realizadas as avaliações, segundo Andrade et al. (1996).

Condutividade elétrica - realizado através do método massal, de acordo com a metodologia proposta pelo comitê de vigor da International Seed Testing Association (ISTA, 1995). Utilizaram-se quatro repetições de 25 sementes, colocadas em recipientes contendo $75 \mathrm{~mL}$ de água destilada, permanecendo em germinador a $25^{\circ} \mathrm{C}$ por períodos de 30 minutos, 4 e 24 horas, após os quais foram realizadas leituras em condutivímetro Digimed-CD 20, sendo os resultados expressos em $\mu$ mhos $\mathrm{cm}^{-1} \mathrm{~g}^{-1}$.

Envelhecimento acelerado - conduzido com quatro repetições de 50 sementes, distribuídas sobre bandejas de tela de alumínio, fixadas no interior de caixas de plástico tipo gerbox, e levadas a câmara do tipo BOD regulada a $41^{\circ} \mathrm{C}$ por 48 horas. Decorrido este período, as sementes foram submetidas ao teste de germinação, conforme descrito anteriormente, realizando-se a avaliação no sétimo dia após a semeadura.

Teste de emergência em casa-de-vegetação - a semeadura foi realizada em caixas multicelulares de poliestireno expandido tipo isopor, com substrato Gioplanta tipo II. Foram utilizadas quatro repetições de 50 sementes, sendo as avaliações realizadas aos 14 e 21 dias após a semeadura.

$O$ delineamento experimental adotado foi 0 inteiramente casualizado, em esquema fatorial $3 \times 4$ (tamanho $x$ lote) com quatro repetições, sendo as médias comparadas pelo teste de Tukey a 5\%. Com exceção do teste de condutividade elétrica, os resultados dos demais testes foram transformados na função arc $\operatorname{sen} \sqrt{x / 100}$. 


\section{RESULTADOS E DISCUSSÃO}

No teste de germinação (TABELA 1) houve diferença significativa entre lotes, para sementes grandes e médias; o lote 2 foi inferior ao lote 1, para sementes grandes e inferior ao lote 3, para sementes médias. Todavia, em relação ao tamanho, não houve diferença significativa dentro de cada lote. Krarup \& Villanueva (1977) observaram que existe uma correlação positiva entre o tamanho do embrião e a percentagem de germinação. Porém, essa tendência não foi verificada no presente trabalho.

Para o teste de tetrazólio não houve diferença significativa entre lotes, nas sementes grandes e na mistura. Nas sementes médias, o lote 1 foi superior aos lotes 3 e 4 . Apenas no lote 1 , as sementes médias apresentaram viabilidade superior em relação à mistura $\mathrm{e}$ às sementes grandes.

No teste de condutividade elétrica, o lote 1 apresentou pior desempenho em comparação aos demais, para os três tamanhos analisados. Observa-se, todavia, que não houve diferença significativa entre tamanhos, dentro de cada lote. No entanto, as sementes médias apresentaram menor perda de lixiviados que as sementes grandes e, consequentemente, maior integridade das membranas, geralmente, associada a sementes de maior vigor.

Para o teste de envelhecimento acelerado, observou-se nas sementes grandes a inferioridade do lote 2 em relação aos demais e, nas sementes médias e na mistura, a superioridade do lote 3 em comparação aos outros. Contudo, não foram verificadas diferenças entre os diferentes tamanhos, dentro de cada lote. As sementes grandes apresentaram menor deterioração em relação às sementes médias, nos lotes 1 e 4 , enquanto que, no lote 3 , as sementes médias e a mistura apresentaram maiores valores, em comparação com as sementes grandes.

Em relação ao teste de emergência de plântulas em casa de vegetação, aos 14 e 21 dias foram observadas diferenças significativas entre lotes, com tendência de caracterização do lote 3 como de melhor desempenho em relação aos demais, nas sementes grandes e na mistura. Entretanto, o lote 2 apresentou pior desempenho relativamente aos outros lotes, nas sementes médias. Analisando o efeito do tamanho, no teste de emergência das plântulas aos 14 dias, verificou-se a superioridade das sementes grandes, no lote 1, da mistura, no lote 2 e das sementes grandes e da mistura, no lote 3 . No teste de emergência das plântulas aos 21 dias, somente no lote 2 ocorreram diferenças significativas entre tamanhos, com as sementes médias apresentando menor valor em relação à mistura.

De uma forma conjunta, não houve diferenças significativas quanto aos diferentes tamanhos de sementes em todos os testes realizados, com exceção do teste de emergência de plântulas em casa de vegetação com

TABELA 1 - Testes realizados em quatro lotes de sementes (grandes-G, médias-M e grandes+médias-G+M) de cenoura cv. Brasília.

\begin{tabular}{|c|c|c|c|c|c|}
\hline & \multirow[t]{2}{*}{ Tamanho } & \multicolumn{4}{|c|}{ Lotes } \\
\hline & & 1 & 2 & 3 & 4 \\
\hline & G & $85 \mathrm{aA}^{*}$ & $69 \mathrm{aB}$ & $79 \mathrm{aAB}$ & $76 \mathrm{aAB}$ \\
\hline Germinação & $\mathrm{M}$ & $81 \mathrm{aAB}$ & $70 \mathrm{aB}$ & $87 \mathrm{aA}$ & $78 \mathrm{aAB}$ \\
\hline \multirow[t]{2}{*}{ (\%) } & $\mathrm{G}+\mathrm{M}$ & $84 \mathrm{aA}$ & 75 aA & $84 \mathrm{aA}$ & 79 aA \\
\hline & $\mathrm{G}$ & $34 \mathrm{bA}$ & 33 aA & $22 \mathrm{aA}$ & $24 \mathrm{aA}$ \\
\hline Tetrazólio & $M$ & $67 \mathrm{aA}$ & $44 \mathrm{aAB}$ & $32 \mathrm{aB}$ & $34 \mathrm{aB}$ \\
\hline (\%) & $\mathrm{G}+\mathrm{M}$ & $32 \mathrm{bA}$ & 36 aA & $44 \mathrm{aA}$ & $34 \mathrm{aA}$ \\
\hline Condutividade & $\mathrm{G}$ & $636 \mathrm{aB}$ & $516 \mathrm{aA}$ & $467 \mathrm{aA}$ & $463 \mathrm{aA}$ \\
\hline elétrica & M & $564 \mathrm{aB}$ & $482 \mathrm{aAB}$ & $434 \mathrm{aA}$ & 459 aA \\
\hline$\mu$ mhos $\mathrm{cm}^{-1} \mathrm{~g}^{-1}$ & $\mathrm{G}+\mathrm{M}$ & $607 \mathrm{aB}$ & 408 aA & 457 aA & $451 \mathrm{aA}$ \\
\hline Envelhecimento & $\mathrm{G}$ & $46 \mathrm{aA}$ & $24 \mathrm{aB}$ & $53 \mathrm{aA}$ & $52 \mathrm{aA}$ \\
\hline \multirow[t]{2}{*}{ acelerado (\%) } & M & $33 \mathrm{aBC}$ & $26 \mathrm{aC}$ & $61 \mathrm{aA}$ & $43 \mathrm{aB}$ \\
\hline & $\mathrm{G}+\mathrm{M}$ & $38 \mathrm{aB}$ & $33 \mathrm{aB}$ & $62 \mathrm{aA}$ & $40 \mathrm{aB}$ \\
\hline Emergência aos & $\mathrm{G}$ & $69 \mathrm{aAB}$ & $48 \mathrm{bC}$ & $75 \mathrm{aA}$ & $64 \mathrm{aB}$ \\
\hline \multirow[t]{2}{*}{14 dias (\%) } & $\mathrm{M}$ & $63 a b A$ & 48 bB & $65 \mathrm{bA}$ & 68 aA \\
\hline & $\mathrm{G}+\mathrm{M}$ & 58 bB & $63 \mathrm{aB}$ & $76 \mathrm{aA}$ & $63 \mathrm{aB}$ \\
\hline Emergência aos & $\mathrm{G}$ & $75 \mathrm{aAB}$ & $60 \mathrm{abC}$ & $81 \mathrm{aA}$ & $69 \mathrm{aBC}$ \\
\hline \multirow[t]{2}{*}{21 dias (\%) } & M & 70 aA & 54 bB & 76 aA & 74 aA \\
\hline & $\mathrm{G}+\mathrm{M}$ & $69 \mathrm{aAB}$ & $67 \mathrm{aB}$ & 79 aA & $71 \mathrm{aAB}$ \\
\hline
\end{tabular}

* Médias seguidas pela mesma letra, minúscula na coluna e maiúscula na linha, não diferem pelo teste de Tukey a $5 \%$. 
avaliação aos 14 dias após a semeadura. Embora pequenas diferenças nos valores médios tenham ocorrido, estas não foram suficientes para detectar diferenças de qualidade entre os diferentes tamanhos de sementes. Os resultados alcançados discordam de Austin \& Longden (1967), Jacobsohn (1978), Jacobsohn \& Globerson (1977) e Usik (1980) ao verificarem que as sementes de menor tamanho apresentaram menores porcentagens de germinação e de emergência em campo e de Krarup \& Villanueva (1977) e Gray \& Steckel (1983) ao constatarem que sementes maiores produziram plântulas mais vigorosas.

A empresa produtora das sementes utilizadas neste trabalho possui como prática usual, após o beneficiamento de suas sementes comerciais, a classificação das sementes em dois tamanhos, grande e médio, visando uma maior uniformidade do material, com o objetivo de melhorar o aspecto visual na comercialização das sementes. Sendo assim, lotes com sementes grandes, médias ou mistura de grandes e médias podem ser comercializados, pois apresentam qualidade fisiológica semelhante. Por outro lado, a utilização pelo produtor de lotes com sementes de tamanho médio seria preferível, pois representaria menor custo, na implantação da cultura, pelo fato de possuir um maior número de sementes por unidade de peso. Além disso, a aparência visual dos lotes, compostos de sementes de mesmo tamanho, favorece sua comercialização, bem como a padronização do tamanho é desejável quando da utilização de semeadura mecanizada.

\section{AGRADECIMENTOS}

Ao Eng. Agr. Gilberto Pozzan - Hortec Sementes Ltda - Bagé/RS, pelo fornecimento dos lotes de sementes utilizados neste experimento.

\section{REFERÊNCIAS BIBLIOGRÁFICAS}

ANDRADE, R.N.B. de; SANTOS, D.S.B. dos; SANTOS FILHO, B.G. dos; MELLO, V.D.C. Testes de germinação e de tetrazólio em sementes de cenoura armazenadas por diferentes períodos. Revista Brasileira de Sementes, v.18, p.108-116, 1996.

AUSTIN, R.B.; LONGDEN, P.C. Some efects of seed size and maturity on the yield of carrot crops. Journal of Horticultural Science, v.42, p.339-353, 1967.
BITTENCOURT, M.L.C. Qualidade das sementes e avaliação das progênies de meios-irmãos de cenoura (Daucus carota L.) 'Brasília'. Viçosa, 1991. 77p. Dissertação (M.S.) Universidade Federal de Viçosa.

BRASIL. Ministério da Agricultura e Reforma Agrária. Regras para análise de sementes. Brasília: SNDA, DNDV, CLV, 1992. 365p.

CARVALHO, N.M.; NAKAGAWA, J. Sementes: ciência, tecnologia e produção. Campinas: Cargill, 1983. 429p.

CASTRO, L.A.B. de. Fatores influenciando o rendimento e a qualidade de sementes de cenoura (Daucus carota L.). Arquivo da Universidade Federal Rural Rio de Janeiro, v.1, p.19-28, 1971.

GRAY, D.; STECKEL, J.R.A. Some effects of umbel order and harvest date on carrot seed variability and seedling performance. Journal of Horticultural Science, v.58, p.73-82, 1983.

GRAY, D.; STECKEL, J.R.A.; BROCKLEHURST, P.A. Some effects of temperature during seed development on carrot (Daucus carota) seed growth and quality. Annals of Applied Biology, v.112, p.367-376, 1988.

HAWTHORN, L.R.; TOOLE, E.H.; TOOLE, V.K. Yield and viability of carrot seeds as affected by position of umbel and time of harvest. Procedings American Society Horticultural Science, v.80, p.401-407, 1962.

INTERNATIONAL SEED TESTING ASSOCIATION. Handbook of vigour test methods. 3.ed. Zürich: ISTA, 1995. 117p.

JACOBSOHN, R. Research on carrot production. Intensifik, n.125, p.93-99, 1978. /Resumo 402 em Horticultural Abstracts, v.50, n.1, p.41, 1980/

JACOBSOHN, R.; GLOBERSON, D. Daucus carota (carrot) seed quality: I. Effect of seed size on germination, emergence and plant growth under subtropical conditions and II. The importance of the primary umbel in carrot - seed production. Intensifik, p.637-646, 1977. /Resumo 8027 em Horticultural Abstracts, v.50, n.11, p.665, 1980/

KRARUP, A.; VILLANUEVA, G. Produccion de semilla de zanahoria: V. Relacion entre el tamaño del embrion y el porcentaje de germinacion de semillas provenientes de distintos ordenes florales. Agro Sur, v.5, p.45-48, 1977.

NASCIMENTO, W.M. Efeito da ordem das umbelas na produção e qualidade de sementes de cenoura. Revista Brasileira de Sementes, v.13, p.131-133, 1991.

POPINIGIS, F. Fisiologia de sementes. Brasília: AGIPLAN, 1985. 289p.

REGHIN, M.Y.; TASHIMA, H.; BALAN, C.C.B.; TRECENTI, R. Produção de sementes de cenoura (Daucus carota L.) pelo sistema semente a semente. Poliagro, v.7, p.65-69, 1985.

USIK, G.E. Effect of seed size on emergence and yield in onions and carrots. Intensifik, p.30-33, 1980. /Resumo $1876 \mathrm{em}$ Horticultural Abstracts, v.51, n.3, p.155-156, 1981/

$\overline{\text { Recebido em } 18.11 .99}$ 